\title{
Conhecimento em Nietzsche, Foucault e Romulo Campos Lins: ancoragens a partir do Modelo dos Campos Semânticos
}

\section{Rodolfo Chaves ${ }^{1}$}

Instituto Federal do Espírito Santo - Ifes

rodolfochaves20@gmail.com

\section{Lígia Arantes Sad ${ }^{2}$}

Instituto Federal do Espírito Santo - Ifes

aransadli@gmail.com

\section{Resumo}

O presente artigo apresenta dois cenários constituídos a partir de resíduos de enunciação apresentados em conversas com alunos, nos quais os respectivos professores adotam o Modelo dos Campos Semânticos para analisarem os significados produzidos pelos participantes, com o propósito de estabelecer um espaço comunicativo, a fim de que produzam novos significados a respeito dos respectivos assuntos tratados. Utilizamos estes cenários para discutir e confrontar os conceitos de conhecimento, segundo o referencial adotado e destacamos que o professor ancorado por tais conceitos, como posto por Friedrich W. Nietzsche, Michel Foucault e Romulo Campos Lins, nutre-se de maior possibilidade de efetuar leituras plausíveis e positivas para entender o que (o porquê, de onde e para quem) o aluno diz o que diz, de modo que possamos intervir nos processos de ensino e, por conseguinte, de aprendizagem.

Palavras-Chave: Conhecimento. Educação Matemática. Produção de Significado. Modelo dos Campos Semânticos.

\section{Knowledge in Nietzsche, Foucault and Romulo Campos Lins: anchorages from the Semantic Fields Model}

\begin{abstract}
The present article presents two scenarios consisting of speech residues presented in conversations with students, in which the respective teachers adopt the Semantic Fields Model to analyze the meanings produced by the participants, with the purpose of establishing a communicative space, in order to produce new meanings regarding their respective subjects. We use these scenarios to discuss and confront the concepts of knowledge, according to the adopted framework, and emphasize that, the teacher anchored by such concepts, as put by Friedrich W. Nietzsche, Michel Foucault e Romulo Campos Lins, has a greater possibility of making plausible readings and positive

1 e 2 Doutores em Educação Matemática pela Unesp/Rio Claro, ambos orientados pelo Prof. Dr. Romulo Campos Lins - in memoriam.
\end{abstract}


readings to understand what (why, from where and to whom) the student says what he says, so that he can intervene in the teaching and, therefore, learning processes.

Keywords: Knowledge. Mathematic Education. Production of Meaning. Semantic Fields Model.

\section{Introdução}

Explicar a constituição do conhecimento na vida do ser humano tem sido historicamente uma empreitada de interesse para estudiosos no campo não somente da Filosofia, mas também da Educação, uma vez que conhecimento e processo de conhecer são preâmbulos epistemológicos esclarecedores ao ensino e à aprendizagem. A pretensão deste texto é fomentar uma discussão relacionada aos argumentos filosóficos de dois destacados pensadores - Friedrich W. Nietzsche e Michel Foucault - a respeito de conhecimento, articulando algumas de suas ideias para uma promissora reflexão ao entendimento de princípios epistemológicos que consideramos sob o olhar do Modelo dos Campos Semânticos (MCS). O MCS foi desenvolvido por Romulo Campos Lins e o utilizamos neste texto como base à análise de conversas ocorridas em sala de aula de Matemática.

Discutir a respeito de desenvolvimentos epistemológicos levou filósofos desde épocas antigas a subtenderem uma relação entre sujeito e objeto - o qual quer apreender, explicar ou inferir. Conhecer, até o início do século XX, era tido como uma ação em que o objeto "existencial" era algo pensado de modo fixo, pois o ser pensante não teria como compreendê-lo de modo dinâmico e transformacional. Daí, direcionado por certa imutabilidade para se chegar a um conhecimento "verdadeiro" do objeto em foco foi preciso o abalo crítico de pensadores como Nietzsche para debater sobre a vontade de verdade - que leva à busca apaixonada e inglória pelo “conhecimento seguro". Uma vontade emanada de crenças em pressupostos da ciência, que queda distanciada do instintivo, conforme são também abordados em trabalhos como os de Vecchia (2014) e Motta (2000), entre outros.

Ainda a favor dessa crítica comparece ao mesmo tempo o erro, o enganar pela máxima do saber certo em demasia (NIETZSCHE, 2002, p. 186), que mostra a insegurança, a debilidade provisória. Erro para quem? A vontade de verdade impregna uma invenção constante de liberdade criadora, de transformações do sujeito para "chegar a ser o que se é", concebido "não como substância dada, mas como forma de a compor" no que está paradoxalmente no processo de "chegar a ser" (LARROSA, 2002, p. 64-65). O aprendiz é envolto em conversas dialógicas com seu conhecimento, com sua invenção constituinte e banidora dos instintos que a propiciaram, para se apoiar em alguma trama ou crença em algo específico, validado por algum poder ou base 
sustentadora. Um poder que lhe dê certa segurança, embora, contraditoriamente, os instintos sejam importantes forças primitivas nas transformações para um novo conhecimento.

Investigar os discursos descontínuos para compreender homogeneidades básicas, procurando particularidades que constituem o conhecimento, a percepção e o saber, são premissas epistemológicas de Foucault em Arqueologia do saber. Um domínio do saber descrito e entrelaçado por conversas, nas quais os discursos ${ }^{2}$ não são meros conjuntos de signos, mas práticas que sistematizam os objetos, "coisas que se transmitem e se conservam, que têm um valor, e das quais procuramos nos apropriar; que repetimos, reproduzimos e transformamos" (FOUCAULT, 1995, p. 139). Nos rastros da interlocução genealógica de Foucault com Nietzsche destacamos deste último sua crítica filosófica à busca da verdade científica.

Não somente utilidade e prazer, mas todo gênero de impulsos tomou partido na luta pelas "verdades"; a luta intelectual tornou-se ocupação, atrativo, dever, profissão, dignidade - o conhecimento e a busca do verdadeiro finalmente se incluíram, como necessidade, entre as necessidades. (NIETZSCHE, 2001, p. 138).

As possibilidades infinitas de interpretação do mundo levam Nietzsche a uma não correspondência ao real, a uma não abrangência da totalidade da experiência humana. A razão também é produtora de equívocos e, por isso, dela podem emanar convicções enganadoras. Desse modo, pode existir uma grande distância entre saber e poder, "há verdades que são mais bem reconhecidas por cabeças medíocres, por lhes serem as mais adequadas; há verdades que encantam e seduzem apenas os espíritos medíocres" (NIETZSCHE, 2002, p.161).

\section{Cenário 1}

Com o propósito de ilustrar os aportes teóricos apresentados, examinemos os seguintes resíduos de enunciação ${ }^{3}$ de Pietro (7 anos) e sua tia Daiana (Professora de Matemática):

\section{Quadro 1 - Resíduos de enunciação do cenário 1}

\section{Pila pro cofrinho do Pietro}

Daiana - Pietro, eu vou te dar esse dinheiro, mas me diga quanto tem aqui (mostrando-lhe uma cédula de R $\$ 2,00$ e uma moeda de R $\$ 1,00)$.

Pietro-Bah! 2 pila e 1 Real!

\footnotetext{
${ }^{2}$ Foucault (1995, p. 135) define discurso como "um conjunto de enunciados", cuja existência é condicionada ao seu momento histórico, às circunstâncias da realização enunciativa.

3 Enunciação é “o ato de enunciar algo a algum interlocutor e, discurso, como uma enunciação ou um enunciado (resíduos de uma enunciação) - "algo com que me deparo e que acredito ter sido dito por alguém.” (LINS, 2012, p. 27). Ambos utilizam, constantemente, um processo de inferência lógica dedutiva por meio da linguagem." (SAD, 1999, p.123). "Já Texto é qualquer resíduo de enunciação para o qual o leitor produza algum significado" (LINS, 1999, p. 88).
} 
Daiana - Como assim? Por que 2 pila e 1 Real? Por que o dinheiro de papel é pila e esse aqui (a moeda) é Real?

Pietro - Porque a Profe ensinou que a moeda do Brasil é o Real!

Daiana - Capaz! Mas tu vais colocar tudo no cofrinho?

Pietro - Vou, né? Daí é 3 pila!

Daiana-Hum! Mas por quê?

Pietro - Porque no cofrinho a gente guarda dinheiro e dinheiro é pila..

Fonte: Fragmento de conversas cos pesquisadores com a Tia do Pietro em 2017.

\section{Ancoragens A}

A palavra conhecimento etimologicamente vem de cognoscere, que pode ser traduzida como conhecer ou saber. A respeito de conhecimento, dentre as muitas significações, destacamos:

ato de perceber ou compreender por meio da razão e/ou experiência. Faculdade de conhecer [...] somatório do se conhece; conjunto das informações e princípios armazenados pela humanidade [...] ato ou faculdade do pensamento que permite a apreensão de um objeto, por meio de mecanismos cognitivos diversos e combináveis, como a intuição, a contemplação, a classificação, a analogia, a experimentação etc. (HOUAISS, et al., 2009, p. 524).

Ao enunciar, "2 pila e 1 Real!" e "Porque a Profe ensinou que a moeda do Brasil é o Real!", Pietro nos permite realizar uma leitura positiva", que ele praticou um "ato ou faculdade do pensamento que permite a apreensão de um objeto, por meio de mecanismos cognitivos diversos $e$ combináveis, como a intuição, a contemplação, a classificação, a analogia, a experimentação" (HOUAISS et al, 2009, p.524).

Em Abbagnano (2000, p.174)

CONHECIMENTO (...) técnica para a verificação de um objeto qualquer [...] Por técnica de verificação deve-se entender qualquer procedimento que possibilite a descrição, o cálculo ou a previsão controlável de um objeto; e por objeto deve-se entender qualquer entidade, fato, coisa, realidade ou propriedade [...] O conhecimento é um procedimento de verificação ou a participação possível em tal procedimento. Como procedimento de verificação, qualquer operação cognitiva visa a um objeto e tende a instaurar com ele uma relação da qual venha a emergir uma característica efetiva deste. Portanto, as interpretações do conhecimento que foram dadas ao longo da história da filosofia podem [...] resumir-se em duas alternativas fundamentais: $1^{\text {a }}$ essa relação é uma identidade ou semelhança (entende-se por semelhança uma identidade fraca e parcial) e a operação cognitiva é um procedimento de identificação do objeto ou de reprodução dele; $2^{a}$ a relação cognitiva é uma apresentação do objeto e a operação cognitiva é um procedimento de transcendência.

4 Pila é como popularmente se denomina uma quantia em dinheiro, no Rio Grande do Sul: R\$ 10,00 equivalem a dez pila.

5 “A leitura positiva dirige-se a saber onde o outro (cognitivo) está, para que eu possa dizer "acho que sei como você está pensando, e eu estou pensando de uma forma diferente [...] a leitura positiva tem por objetivo [...] dizer, mapear o terreno ao mesmo tempo que trata de saber onde o outro está" (LINS, 2012, p. 23-24). 
Da mesma forma, o resíduo de enunciação, "2 pila e 1 Real!", é uma apresentação de um objeto e, portanto, configura-se como uma relação cognitiva. Analogamente, ao enunciar "Porque a Profe ensinou que a moeda do Brasil é o Real!", Pietro efetuou uma operação cognitiva de identificação e reprodução que, segundo Abbagnano (2000), é um procedimento de transcendência.

Lins (2012, p. 12) propõe como recaracterização da noção de conhecimento: "Um conhecimento consiste em uma crença-afirmação (o sujeito enuncia algo em que acredita) junto com uma justificação (aquilo que o sujeito entende como lhe autorizando a dizer o que diz)."

Observemos que Pietro, ao enunciar que lhe é dado "2 pila e 1 Real" e não 3 pila ou R\$ 3,00, à luz do MCS, não constitui um erro, mas uma crença-afirmação, pois disse algo em que acredita. Sua justificação advém do resíduo de enunciação de que a "Profe ensinou a que a moeda do Brasil é o Real", que funciona como uma estipulação local ${ }^{6}$.

Esperar que uma criança de 7 anos entenda que o objeto ${ }^{7}$ moeda, empregado pela professora, significa unidade monetária, é ter expectativa de que Pietro, enquanto leitor de tal enunciação, esteja em um espaço comunicativo além de sua compreensão, pois, devido ao meio sociocultural em que vive e às experiências que compartilha, moeda não assume outro significado senão o de dinheiro de metal. Podemos então dizer que, naquele instante, ele operava em um campo semântico ${ }^{8}$ que diferencia cédula, "pila", de moeda, "Real". Mas, ao relatar que o destino de "2 pila e 1 Real" é o seu cofrinho, passou a operar em um campo semântico que permitiu efetuar a união entre "pila" e "Real" transformando o resultado em "pila", pois aí o todo - o conteúdo de seu cofrinho - é "dinheiro" e, segundo ele, "no cofrinho a gente guarda dinheiro e dinheiro é pila"; isto é, se Pietro não vê de que material é constituído o "Real" tudo passa a ser pila, pois, para ele, pila é dinheiro e dinheiro se guarda no cofrinho. Pelo MCS dizemos que Pietro, no que se refere a dinheiro, nos levou a identificar dois modos de produção 9 de significado: (1) cédula é pila; (2) moeda é Real.

Ao afirmar que "dinheiro é pila" ele apresentou um resíduo de enunciação que funciona como uma estipulação local ou uma verdade absoluta justificada e "o conjunto de estipulações

\footnotetext{
6 "Estipulações locais, que são, localmente, verdades absolutas, que não requerem, localmente, justificação" (LINS, 2012, p. 26).

7 “Objeto é aquilo para que se produza significado" (LINS, 2012, p. 28), ou “"algo' do qual o sujeito pode falar a respeito" (SAD, 1999, p. 126).

${ }^{8}$ É "um processo de produção de significado, em relação a um núcleo, no interior de uma atividade [...] sendo um processo, ao ser colocado em marcha cria condições para sua própria transformação" (LINS, 2012, p. 17).

${ }^{9}$ Modos de produção de significado são “"campos semânticos idealizados' que existem na forma de repertórios segundo os quais nos preparamos para tentar antecipar de que é que os outros estão falando ou se o que dizem é legítimo ou não" (LINS, 2012, p.29).
} 
locais - que funcionam como verdades absolutas locais - constitui um núcleo com relação ao qual produzo significados/conhecimentos" (LINS, 1999, p. 88).

De outra forma, se analisarmos a enunciação de Pietro, a partir de Houaiss et al (2009) e Abbagnano (2000), podemos afirmar que ele enunciou o que compreendeu, pois, advém de uma razão (a Profe ensinou) ou uma experiência (moeda é o objeto ${ }^{10}$ e no Brasil se chama Real).

Ao compararmos conhecimento em Houaiss et al (2009) e Abbagnano (2000) com o conceito apresentado em Lins (2012), verificamos que há entre eles semelhança e não uma tricotomia. Uma leitura plausível ${ }^{11}$ nos permite observar que as três definições compartilham o mesmo espaço comunicativo ${ }^{12}$. E, assim, podemos afirmar que Pietro produziu conhecimento ao enunciar "2 pila e 1 Real! Porque a Profe ensinou que a moeda do Brasil é o Real!".

Ademais, no que se refere ao entendimento de conhecimento para o MCS, é providencial destacar que:

- conhecimento é algo do domínio da enunciação,

- sempre há um sujeito do conhecimento (e não do conhecer),

- o papel da justificação é produzir legitimidade para minha enunciação,

- toda produção de conhecimento é feita na direção de um interlocutor que, acredito, produziria a mesma enunciação com a mesma justificação (LINS, 1999, p. 88).

Se voltarmos ao Cenário 1, identificamos que, a resposta "2 pila e 1 Real!... Porque a Profe ensinou que a moeda do Brasil é o Real" é do domínio da enunciação; Pietro é o sujeito desse conhecimento e há uma justificação produzindo legitimidade, portanto, segundo o MCS, Pietro produziu conhecimento.

É pertinente lembrar que "nenhum conhecimento é produzido no mundo ingenuamente. Aquele que o produz, que o enuncia, já fala em uma direção (o interlocutor) na qual o que ele diz, e com a justificação que tem, pode ser dito. Esta direção representa uma legitimidade que internalizou o sujeito, e este é o sujeito ${ }^{13}$ de um saber ventríloquo" (LINS, 2012, p.13). É este o sentido do diálogo que foi estabelecido entre Pietro e Daiana, professora de Matemática.

\footnotetext{
${ }^{10}$ Por objeto deve-se entender qualquer entidade, fato, coisa, realidade ou propriedade (ABBAGNANO, 2000).

11 “Plausível porque 'faz sentido', ‘é aceitável neste contexto' [...] A leitura plausível se aplica de modo geral aos processos de produção de conhecimento e significado; ela indica um processo no qual o todo do que eu acredito que foi dito faz sentido" (LINS, 2012, p. 23).

12 “[...] o compartilhamento de interlocutores constitui um espaço comunicativo" (LINS, 1999, p.88).

13 “É melhor dizer assim do que usar a convenção usual e dizer que 'o sujeito internalizou x' (uma legitimidade, um modo de produção de significado, ou, como em Vigotski, uma forma social e culturalmente produzida. Com a nova formulação podemos falar de legitimidades e modos de produção de significado legítimos sem precisarmos de grupos de pessoas)" (Nota do autor).
} 


\section{Cenário 2}

Os resíduos de enunciação a seguir são frutos de uma intervenção, que culminou na ação de caráter lúdico, na qual utilizamos instrumentos para determinar distância e direção, efetuando leituras a partir de coordenadas polares, possibilitando realizar algumas análises interessantes quanto à dinâmica da produção de significado, para dar conta da caracterização do pensamento espacial apresentado pelos envolvidos.

Após realizarem suas medições (distâncias e direções), ao final do processo, para cada grupo havia um baú (o tesouro) contendo moedas de chocolate, balas coloridas, do tipo gometes, e 2 livros: $O$ homem que calculava, de Malba Tahan, e $O$ diabo dos números, de Hans Magnus Enzensberger. A professora (Vera) sugeriu que cada grupo (de 3 alunos) repartisse as guloseimas entre seus componentes.

\section{Quadro 2 - Resíduos de enunciação do cenário 2}

\section{Caça ao tesouro}

Alex - Profe, no meu sobrou 1 gomete e faltou 1 chocolate!

Isadora - No meu sobrou 1 chocolate, que demos para Profe Maísa, e 2 gometes, que demos para Profe Patrícia!

Vera-Que bom, Isadora, vocês tomaram uma ótima iniciativa. Muito bem!

Luiza - Profe, no meu faltou $R \$ 0,05$, sobrou 1 gomete roxa, faltou 1 gomete amarela e as verdes e vermelhas deram para dividir certinho!

Vera - Como assim, Luiza? Explica à classe como vocês repartiram o tesouro.

Luiza - Nós separamos primeiro as moedas e deu $R \$ 13,45$. Se tivesse mais $R \$$ 0,05, daria $R \$ 13,50 \ldots$ Daí dá pra dividir pra 3 e fica $R \$ 4,50$ pra cada.

Vera - E como vocês repartiram as gometes?

Luiza - No nosso pacote tem 11 gometes amarelas, 13 roxas, 12 verdes e 12 vermelhas. As vermelhas e as verdes foram fáceis, pois dá 4 de cada cor para cada um, mas as roxas têm 13 então dá 4 pra cada e ainda sobra 1; mas as amarelas só tem 11 então fica faltando 1 pra dar 4 pra cada.

Vera - E por que você não pega a roxa que sobrou pra completar a amarela que falta?

Luiza - Porque aí não vai ser divisão certinha, da mesma cor!

Vera - Bãh! Mas escuta, vocês estão dividindo dinheiro ou chocolate, bala ou objeto colorido? Me diga uma coisa: quantas moedas de chocolate vocês têm?

Luiza - 37: são 7 moedas de $R \$ 1,00 ; 7$ de $R \$ 0,50 ; 7$ de $R \$ 0,25 ; 8$ de $R \$ 0,10$ e 8 de $R \$ 0,05$.

Vera - Hum, interessante! E se vocês dividissem a quantidade de chocolates não levando em conta o valor das moedas, como ficaria?

Luiza - Daí sobraria um chocolate, porque se eu dividir dá 12 pra cada um e sobra 1 chocolate. Mas não é só chocolate é moeda de chocolate então nós dividimos o valor, mas também não bateu. Chocolate sobra 1 e dinheiro falta $R \$ 0,05$. O que a gente faz?

Vera - Mas me diz uma coisa: por que vocês fizeram a divisão como dinheiro e não como chocolate?

Luiza - Porque se fosse pra dividir chocolate a senhora colocaria no baú outro tipo de chocolate sem ser moeda!

Fonte: Fragmento de pesquisa de pós-doutorado desenvolvido junto ao PPGEMEF/UFSM/CCNE/DMAT. 


\section{Ancoragens B}

Chaves (2004) relaciona Foucault a Nietzsche, afirmando que o primeiro tomou o segundo como fonte para discutir conhecimento. Para tal, alega que Foucault (2001) aponta a associação de Nietzsche como fonte primária, pois, "foi esse mito que Nietzsche começou a demolir ao mostrar, em numerosos textos já citados, que por trás de todo conhecimento, o que está em jogo é uma luta de poder. O poder político não está ausente do saber, ele é tramado com o poder." (FOUCAULT, 2001, p. 48-49).

É nesse sentido que, no MCS, o o cerne da questão não é o aspecto meritocrático do erro; estar certo - portanto apto - ou errado - portanto excluído - pelo poder não transforma, apenas rotula o aluno em castas, banindo-o ou chancelando-o. O que é transformador no MCS é procurar entender o que leva o aluno a dizer o que diz e a partir de que lugar o diz; por isso, entendemos a produção de significado como "o aspecto central de toda aprendizagem - em verdade o aspecto central de toda a cognição humana" (LINS, 1999, p. 86). Especificamente, significado "é o conjunto de coisas que se diz a respeito de um objeto. Não o conjunto do que se poderia dizer, e, sim, o que efetivamente se diz no interior de uma atividade. Produzir significado é, então, falar a respeito de um objeto" (LINS; GIMENEZ, 1997, p. 145-146).

Luiza opera em um modo de produção de significado em que a partilha realizada é dinheiro, pois, possivelmente, entendera que assim deveria ser, visto que na caixa havia um tesouro. Observamos que Vera buscou um entendimento, uma leitura, da enunciação de Luiza, para entender o que levou Luiza a dizer o que disse e a partir de que lugar. Se agisse meritocraticamente, Vera fixaria Luiza em casta, chancelando-a: errada! Mas ao invés disso, optou por estabelecer um espaço comunicativo com ela para saber como e de onde a mesma operava: "não sei também onde você está (sei apenas que está em algum lugar); preciso saber onde você está para que eu possa ir até lá falar com você e para que possamos nos entender" (LINS, 1999, p. 85).

Foucault (2001) apresenta a concepção de que o conhecimento é uma invenção, assim

só existe na medida em que, entre o homem e o que ele conhece, se estabelece, se trama, algo como uma luta [...] Nele, há sempre alguma coisa que é da ordem do duelo e que faz com que o mesmo seja sempre singular. E é singular porque esquematiza e ignora as diferenças; e, por isso, ao esquematizar, configura-se sempre como uma certa relação estratégica em que o homem se encontra situado. Tratando-se de uma estratégia, passa a ser o efeito de uma batalha, só ocorrendo sob a forma de um certo número de atos diferentes entre si (CHAVES, 2004, p. 70-71). 
Todavia, a obra referendada nessa citação, chama atenção para o fato de que a ideia de batalha, no senso comum, não se encontra no mesmo espaço comunicativo que Nietzsche se encontra; isto é, para Nietzsche (2001) e Foucault (2001) batalha não se refere à briga ou discussão. "Para Nietzsche, confronto, batalha [...] significa, antes de qualquer coisa, rever valores, ir além deles (transvalorizar-se)" (CHAVES, 2004, p. 71). Um exemplo disso observa-se quando Vera, ao invés de dizer que tal partilha está certa (ou não), ela apresenta perguntas para levar os alunos a confrontarem seus valores e verdades. Mas, à luz do MCS, ao efetuar tais perguntas, Vera busca por em curso um processo de estranhamento deixando fluir outras legitimidades com cada um dos seus interlocutores. Tal estratégia sob o MCS, de acordo com Oliveira (2012), é um movimento de descentramento, no qual

o que importa mesmo é que exista de um lado aquele para quem uma coisa é natural - ainda que estranha - e de outro aquele para quem aquilo não pode ser dito. Esta é a característica fundamental deste processo de estranhamento, um processo que pode ser visto da primeira série do Ensino Fundamental em diante (LINS, 2004, p. 116).

Em Luiza e Vera é possível observar que a professora intenciona uma transvalorização ao questionar a respeito do tipo de partição realizada. O mesmo ocorreu em Cenário 1, no qual Daiana, dialogicamente, leva Pietro a travar uma batalha com o conhecimento que possui (1 pila $\neq$ $\mathrm{R} \$ 1,00)$, na tentativa de estabelecer uma interlocução.

Se Vera não inquerisse Luiza, o resíduo de enunciação "no meu grupo faltou $R$ \$ 0,05 [...]" poderia ser entendido como uma estipulação local, que é uma verdade absoluta, não requerendo, localmente uma justificação, como apontou Lins (2012, p. 26). Mas, quando Vera questiona "Como assim, Luiza? Explica à classe como vocês repartiram o tesouro" - o diálogo estabelecido permite que Luiza produza conhecimento, apresentando além da crença-afirmação sua justificação. Analogamente, se Daiana não inquerisse Pietro a respeito de seu resíduo de enunciação ( $a$ moeda é $R \$ 1,00$ porque a Profe [...]), o mesmo poderia ser entendido como uma estipulação local, uma verdade, não requerendo, uma justificação para produzir conhecimento. É nesse sentido que o duelo - como apresentado por Nietzsche - se trava, na tentativa de estabelecer um espaço comunicativo para saber de onde o autor fala, em que direção, a partir de que referências.

No parágrafo antecedente exemplificamos uma convergência às concepções de conhecimento em Nietzsche (2001), Foucault (2001) e Lins (2012; 1999), mas no Sigma-T ${ }^{14}$, nos idos de 2003, havia um dilema quanto às colocações de Nietzsche e Lins. O primeiro trata do sintagma "construção" enquanto que o segundo refere-se à "produção de conhecimento". A fim de

\footnotetext{
${ }^{14}$ Grupo de pesquisas, cujo líder foi o Romulo, formado por pesquisadores que se dedicam ao estudo do MCS.
} 
identificarmos se, entre tais sintagmas, é possível que haja (ou não) similaridades ou convergências de significação, consultamos também o dicionário de Houaiss et al (2009). Uma vez que adotamos de Lins (1993), descreve-se se um caminho para refletir sobre estas similaridades e diferenças:

Que sentido pode haver, para um espectador, numa discussão entre dois pesquisadores, um deles dizendo que conhecimento é transmitido, e outro dizendo que conhecimento é construído, se não está claro o que um e outro chamam de "conhecimento"? E quantas vezes não fica a audiência tentando chegar a adequação das afirmações de um e de outro com a "realidade", sem perceber que mesmo esta noção é objeto de intensos e profundos debates em Epistemologia? [...] É preciso entender que quando este ou aquele autor diz que o conhecimento é construído, e fala de "dados de pesquisa" que confirmam sua tese, ele está desde o princípio falando segundo uma perspectiva epistemológica que pode ser completamente incompatível com a do leitor e mesmo com a dos seus sujeitos de pesquisa. De modo geral, posições epistemológicas são elementos essenciais [...] (LINS, 1993, p. $78)$.

Outrossim, Lins (1993) nos lembra que, segundo a concepção vigotskiana, todo conhecimento é produto social e resulta de processos de interação humana, assim como os resíduos de enunciação apresentados nos Cenários 1 e 2. Tal processo pode ser entendido como "resultado do esforço de um escritor" - um dos significados de produção em Houaiss et al (2009, p. 1556) - e desta forma, convergimos para o sintagma produção de conhecimento. Todavia, o conhecimento, enquanto produto social, é fruto de um "trabalho de organização e criação de (algo)", segundo um dos significados de construção em Houaiss et al (2009, p. 532); logo, o conhecimento também decorre da construção.

É nesse sentido que a produção de conhecimento posta por Lins converge com a

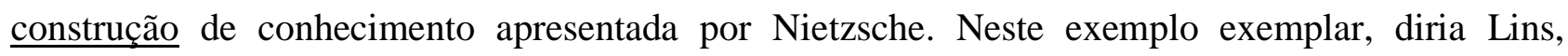
Daiana, sem imputar o tom meritocrático de erro, leva Pietro a autoquestionar suas próprias verdades. Mas, porque "nenhum conhecimento vem ao mundo ingenuamente" (LINS, 2012, p. 13), Daiana, como enunciadora - e falando na direção do interlocutor com quem dialoga, utiliza os mesmos sintagmas que Pietro - "pila" e "Real" - com o propósito de observar de onde ele fala e por que fala.

A partir de tais leituras e exemplos vividos, entendemos ser oportuno propor que a produção de conhecimento, segundo o MCS, aproxima (e converge) da (para a) construção de conhecimento em Nietzsche, pois, ao procurar entender o que leva o aluno a dizer o que diz e a partir de que lugar o diz, tomamos a produção de significado como processo educacional propício para especular a cognição humana.

Devido aos limites deste texto e a nosso escopo no processo, passamos a culminar nossa análise onde (e se) há convergência e similaridades (ou não) entre a ideia de conhecimento em 
Nietzsche/Foucault e Lins. Tal como Nietzsche, entendemos que um conhecimento não se constrói/produz a partir da aceitação de nossas verdades, mas a partir do questionamento das mesmas com respeito de algo a ser conhecido. Desta forma, tratados adequadamente, o "erro" e a dúvida constituem-se pontos relevantes para construir/produzir conhecimento, estabelecendo interlocuções a partir do compartilhamento de espaços comunicativos. Assim, não é o resultado de uma questão ou o "acerto" de uma demonstração matemática que nos levarão a construção/produção de conhecimento a respeito de um procedimento ou de uma teoria, mas o questionamento, a análise do processo, a justificação de uma crença-afirmação ou o confronto com outras.

Lins $(2012$; 1999) chama atenção para o fato de que as maneiras pela qual se produz conhecimento dependem de múltiplas variáveis e parâmetros, componentes das dinâmicas de uma dada cultura e, portanto, não há como entender única uma produção válida, viável ou correta, no que se refere aos contextos e aos indivíduos. Logo, na classe da Vera, os alunos Alex, Isadora e Luiza produziram significados e, no confronto, também conhecimento. A classe do $5^{\circ}$ ano, é homogênea quanto à faixa etária e no que se refere ao aspecto socioambiental - são moradores da zona rural de Santa Maria, mas as suas respectivas interações e experiências socioculturais levaram (os atores desse processo) a produções de conhecimento que não podemos afirmar como mesmas. Isso porque, para tal, precisaríamos mergulhar em uma análise epistemológica de outros discursos e constituições deles a respeito da situação e objetos envolvidos.

\section{Algumas considerações}

Fruto de nossas análises e reflexões a respeito dos conceitos apresentados, entendemos que buscar alicerces epistemológicos - e não apenas didáticos ou pedagógicos - pode vir a auxiliar o professor a romper dispositivos de controle que o impedem de transvalorizar-se e à sistematizar suas observações, práticas e ações.

Se tomarmos os sintagmas "construção de conhecimento" e "produção de conhecimento" como sinônimos e se estendermos a concepção de conhecimento, que por hora adotamos do MCS, à visão foucaultiana, logo nietzscheniana de conhecimento, teremos disponível um espectro mais amplo para análise das dinâmicas da produção de significados, seja em nossas pesquisas acadêmicas ou ao empreendermos nossas ações em sala de aula.

O entendimento, por parte do professor, de conceitos tomados pelo MCS - como conhecimento, epistemologia, produção de significado, espaço comunicativo, leitura plausível, leitura positiva, dentre outros - pode vir a possibilitar um olhar diferenciado aos significados 
produzidos pelos alunos em um contexto educativo, propiciando intervir sistematicamente nos processos de ensino e de aprendizagem.

Os Cenários que apresentamos permitem-nos analisar o quão profícuo tem sido, aos processos de ensino e de aprendizagem, quando os professores ancoram-se nas concepções apresentadas, sejam elas à luz do MCS, nietzschenianas ou foucaultianas. Trabalhar no viés do MCS considerando a produção de significado como aspecto primordial da aprendizagem permite que professores e futuros professores repensem suas práticas (ações docentes, no campo políticofilosófico) de forma que possamos propor: (i) "uma reflexão que não se restrinja à preparação para a ação, mas que seja (esteja em) a própria ação" (LINS, 1999, p. 94); (ii) uma "Educação Matemática que produza legitimidade, dentro da escola, para os modos de produção de significado da rua como ato político e ato pedagógico" (LINS, 1999, p. 92); e, portanto, (iii) uma escola que não sufoque a liberdade nem se fixe na intenção comum de negar o indivíduo.

\section{Referências}

ABBAGNANO, N. Dicionário de Filosofia. 4.ed. São Paulo: Martins Fontes, 2000.

CHAVES, R. Por que anarquizar o ensino de Matemática intervindo em questões socioambientais? 391p. Tese (Doutorado em Educação Matemática), PPGEM-IGCE-UNESP, Rio Claro, 2004.

FOUCAULT, M. A verdade e as formas jurídicas, 2.ed. 2.reimp. Rio de Janeiro: Nau, 2001.

. A arqueologia do saber. Tradução de Luiz Felipe B. Neves. 4 ed. Rio de Janeiro: Forense Universitária, 1995.

HOUAISS, A.; VILLAR, M.S.; FRANCO, F.M. de M. Dicionário Houaiss da língua portuguesa. 1.ed., 1.reimp. Com alterações. Rio de Janeiro: Objetiva, 2009.

LARROSSA, J. Nietzsche \& a Educação. Belo Horizonte: Atual, 2002.

LINS, R.C. O Modelo dos Campos Semânticos: estabelecimento e notas de teorizações. In: ANGELO, C.L. et al (org.). Modelo dos Campos Semânticos e Educação Matemática: 20 anos de história. São Paulo: Midiograf, 2012. p.11-30.

Por que discutir teoria do conhecimento é relevante para a Educação Matemática. In: BICUDO, M.A.V. (Org.). Pesquisa em Educação Matemática: concepções \& perspectivas. São Paulo: Editora UNESP, 1999.

LINS, R.C.; GIMENEZ, J. Perspectivas em aritmética e álgebra para o século XXI. 3. ed. Campinas: Papirus, 1997. (Perspectivas em Educação Matemática).

LINS, R.C. Epistemologia, História e Educação Matemática: tornando mais sólida as bases da pesquisa. Revista da Sociedade Brasileira de Educação Matemática - São Paulo, Ano 1, n.1, set./1993, p.75-91.

A framework for understanding what algebrraic thinking is. 330p. Phd Thesis. Inglaterra: University of Notttingham - UK, 1992.

MOTTA, F.C.P. O que é Burocracia. São Paulo: Brasiliense, 2000. 
NIETZSCHE, F.W. Além do bem e do mal: prelúdio a uma filosofia do futuro. 2.ed, 7.imp. São Paulo: Companhia das Letras, 2002.

A gaia ciência. S. Paulo: Companhia das Letras, 2001.

OLIVEIRA, V.C.A. de. Sobre as ideias de estranhamento e descentramento na formação de professores de Matemática. In: ANGELO, C.L. et al (org.). Modelo dos Campos Semânticos e Educação Matemática: 20 anos de história. São Paulo: Midiograf, 2012. p.199-216.

SAD, L.A. Cálculo Diferencial e Integral: uma abordagem epistemológica de alguns aspectos. 371p. Tese de Doutorado (em Educação Matemática), PPGEM-IGCE-UNESP. Rio Claro, 1999.

STIRNER, M. O falso princípio da nossa educação. São Paulo: Imaginário, 2001.

VECCHIA, R.B.D. A filosofia da filosofia de Nietzsche: uma releitura de F. Kaulbach. Vitória (ES), v.3, n.2. Revista Sofia. PPG em Filosofia da Ufes. Jul./Dez.2014 eletrônica, p.216-231.

Submetido em maio de 2018

Aprovado em junho de 2018 